intraventricular injections of eserine. Neuropharmacology, 1972, 12, 275-281.

Booth, D. A. Mechanism of action of norepinephrine in eliciting an eating response on injection into the rat hypothalamus. Journal of Pharmacology \& Experimental Therapeutics, 1968,

Brophy, P. D. Angiotensin-induced drinking in the cat: A dose-response and biochemical analysis. Unpublished doctoral dissertation, Southern Illinois University at Carbondale, 1973.

Brophy, P. D., \& Levitt, R. A. Dose-response analysis of angiotensin- and renin-induced drinking in the cat. Pharmacology, Biochemistry \& Behavior, in press.

Epstein, A. N., Fitzsimons, J. T., \& Johnson, A. K. Prevention by angiotensin II antiserum of drinking induced by intracranial angiotensin. Journal of Physiology, 1973, 230, 42-43.

Feldberg, W., \& Sherwood, S. L. Behaviour of cats after intraventricular injections of eserine and DFP. Journal of Physiology, 1954, 125, 488-500.

Fitzsimons, J. T. Thirst. Physiological Reviews, 1972, 52, 468-561.

Fitzsimons, J. T., \& Setler, P. E. Catecholaminergic mechanisms in angiotensin-induced drinking. Journal of Physiology, 1971, $218,43-44$

Ganten, D., Boucher, R., \& Genest, J. Renin within the central nervous sy stem. Brain Research, 1971, 33, 557-563.

Ganten, D., Minnich, J. L., Granger, P., Hayduk, H., Brecht, H. M., Barbeau, A., Boucher, R., \& Genest, J. Angiotensin-forming enzyme in brain tissue. Science, 1971, 173, 64-65.

Giardina, A. R., \& Fisher, A. E. Effect of atropine on drinking induced by carbachol, angiotensin and isoproterenol.
Physiology \& Behavior, 1971, 7, 653-655.

Goodman, L. S., \& Gilman, A. The pharmacological basis of therapeutics. New York: Macmillan, 1970.

Gross, F. Angiotensin. International Encyclopedia of Pharm acology \& Therapeutics, 1971, 1, 73-286.

Guyton, A. C. Textbook of medical physiology. Philadelphia: Saunders, 1971.

Houpt, K. A., \& Epstein, A. N. The complete dependence of beta-adrenergic drinking on the renal dipsogen. Physiology \& Behavior, 1971, 7, 897-902.

Jasper, H. H., \& Ajmone-Marsan, C. Diencephalon of the cat. In D. E. Sheer (Ed.), Electrical stimulation of the brain. Austin: University of Texas Press, 1961.

Myers, R. D. Emotional and autonomic responses following hypothalamic chemical stimulation. Canadian Journal of Psychology, 1964, 18, 6-14.

Routtenberg, A. Drinking induced by carbachol: Thirst circuit or ventricular modification? Science, 1967, 157, 838-839.

Routtenberg, A. Intracranial chemical injection and behavior: A critical review. Behavioral Biology, 1972, 7, 601-641.

Sturgeon, R. D., Brophy, P. D., \& Levitt, R. A. Drinking elicited by intracranial microinjection of angiotensin in the cat. Pharm acology, Biochemistry \& Behavior, 1973, 1, 353-355.

Sturgeon, R. D., \& Levitt, R. A. Angiotensin-induced drinking in the cat: A neuroanatomical analysis. Physiological Psychology, in press.

White, C. S., Levitt, R. A., \& Boyer, S. Drinking elicited by CNS injection of angiotensin in the rat. Psychonomic Science, $1972,26,283-284$.

(Received for publication March 11, 1974.)

\title{
Impact of sound effects and dramatic speech style on speaker perception, attitudes, and speech recall
}

\author{
JOE VINCENZO and CLYDE HENDRICK* \\ Kent State University, Kent, Ohio 44242
}

\begin{abstract}
Under the guise of serving in an experiment on speech perception, Ss listened to a short speech under one of four conditions. The speech was spoken either dramatically or seriously, and the speech either was or was not accompanied by sound effects. Measures were taken on Ss' moods, attitude, and recall of the speech. Results showed more persuasion for the serious than for the dramatic version of the speech. However, the serious/dramatic and sound/no-sound manipulations interacted in determining mood ratings. Overall, attitudinal acceptance was independent of the affect expressed by Ss. The results were interpreted as supporting Leventhal's (1970) parallel response model.
\end{abstract}

In a recent attitude study, Galizio and Hendrick (1972) exposed Ss to four folk songs, each of which

*R equests for reprints should be addressed to Clyde Hendrick, Department of Psychology, Kent State University, Kent, Ohio 44242 . either did or did not have guitar accompaniment and each of which was either sung or dramatically spoken. Results indicated that a communication accompanied by instrumental music enhanced both persuasion and 
positive affective reactions. The "eating studies" by Dabbs and Janis (1965) and Janis, Kaye, and Kirschner (1965) were cited in support of these findings. These studies found that eating while reading, but not before or after reading, enhanced acceptance of a persuasive communication. Dabbs and Janis (1965) ascribed this result to a momentary mood of compliance created by the pleasant activity of eating. Both sets of data considered jointly suggest that positive affect or arousal may enhance persuasion.

The purpose of the present study was to generalize the results for arousal states to other potentially emotional stimuli (actually 11 sound effects), and to find out if the speaker's emotional voice quality (serious or dramatic) affected the S's perceptions of the speaker, attitude on the issue, and recall of a communication. Galizio and Hendrick (1972) imply that such generalization should occur.

Ss were exposed to one of four experimental conditions. Each group of Ss listened to one communication, which was spoken seriously with no sound effects, or seriously with sound effects, or dramatically with no sound effects, or dramatically with sound effects. The sex of the Ss was also varied. These variations constituted a 2 by 2 by 2 factorial design.

\section{METHOD}

\section{Subjects}

Freshman psychology students enrolled at Kent State University served as Ss for an experiment described as a study in speaker perception. Data were collected on the same day during morning and afternoon hours. The Ss were assigned randomly to one of four conditions. There were $42 \mathrm{Ss}$ in the serious/no-sound condition, $37 \mathrm{Ss}$ in the serious/sound condition, $42 \mathrm{Ss}$ in the dramatic/no-sound condition, and $38 \mathrm{Ss}$ in the dramatic/sound condition. The final sample consisted of 159 male and female Ss. The order in which these conditions were presented to groups was chosen randomly.

\section{The Communication}

A persuasive communication was devised which advocated specific alterations in the present educational institution. The first author recorded the communication on one channel of a Sony two-channel stereo system. The communication was recorded in one of two ways. In one delivery, the speaker was serious in his voice quality; in another delivery, he spoke dramatically. All other aspects of the communication were kept constant.

Eleven sound effects were selected from available recorded sources. The sound effects were recorded on the second channel in locations most congruent with the content of the communication. The following are three excerpts from the communication: "Such starving of affiliation needs could lead an individual to hysteria." At this point, the voice of a woman, screaming, was heard. "Experimental studies in this area have shown that this type of environment enhances aggression." Here, Ss heard the sound of an angry crowd. "This would omit much of the structured course work and skyrocket learning." The sound of a rocket taking off was heard. Thus, there was a serious and a dramatic spoken version of the communication, and sound effects or their absence on the second channel of the tape. The duration of the communication was 5:17.

\section{Procedure}

The second author served as the main $\mathrm{E}$ in each condition. Ss were told that they would hear a short speech, and that the $\mathrm{E}$ was interested in how different forms of communication affected their perception of the speaker. The nature of the questionnaire they would receive was mentioned briefly in advance.

At this point, the tape was begun. Because of anticipated social comparison, an attempt was made by the Es to either conceal facial expressions or react mildly to the communication.

Immediately following the communication, the questionnaires were distributed. The instructions were explained in detail. When all the questionnaires were completed, Ss were debriefed, asked not to talk about the experiment, and then dismissed.

\section{Questionnaire}

Ss completed the questionnaire immediately after listening to the communication. This form was divided into three sections: speech perception, impressions of the speech, and recollections of the speech.

The first section consisted of 15 mood dimensions (e.g., like-dislike). The ratings were made on 7-point semantic differential scales, with the mood pairs anchoring the ends of the scale. Positive and negative mood words were counterbalanced across the right and left side of the rating form.

The second section consisted of nine questions assessing the S's attitude toward the content of the speech. For each question, there was a 5-point scale with endpoints labeled "disagree completely" and "agree completely." The nine ratings were summed to yield a total attitude score which could range between 9 and 45, with a higher score indicating greater acceptance of the communication.

The third section consisted of nine multiple-choice questions assessing the S's recollections of the communication. The correct answers were summed to yield a total recall score.

\section{RESULTS}

The results are presented separately for the mood ratings, the attitude measure, and recall measure.

\section{Mood Ratings}

A 2 (serious/dramatic) by 2 (sound effects/no sound effects) by 2 (male and female Ss) analysis of variance was performed on each of the 15 mood ratings.

The most important and consistent result was an interaction of the sound/no sound and serious/dramatic speaking style for several of the mood dimensions. A summary of these interaction means is shown in Table 1.

For the first mood rating (distrust/trust), the Ss who experienced a serious speech with no sound made the more positive rating. The means were 4.7 for the serious/no-sound condition, 4.4 for the dramatic/sound condition, 4.1 for the serious/sound condition, and 3.1 for the dramatic/no-sound condition. The interaction was highly significant $(F=8.69, \mathrm{df}=1 / 151, \mathrm{p}<.004)$.

The same pattern of results was obtained for tense/relaxed. The means were 5.6 for the serious/no-sound condition, 5.6 for the dramatic/sound condition, 5.5 for the serious/sound condition, and 4.4 for the dramatic/no-sound condition. This effect was again highly significant $(\mathrm{F}=7.54, \mathrm{p}<.006)$.

Exactly the same interaction pattern was also obtained for the mood dimensions of insincere/sincere $(\mathrm{F}=4.98, \mathrm{p}<.03)$, disagree/agree $(\mathrm{F}=4.77, \mathrm{p}<.03)$, and unpersuasive/persuasive $(\mathrm{F}=6.52, \mathrm{p}<.01)$. These 
Table 1

Means for Mood Ratings

\begin{tabular}{|c|c|c|c|c|}
\hline \multirow[b]{2}{*}{ Mood Dimension } & \multicolumn{2}{|c|}{ Serious } & \multicolumn{2}{|c|}{ Dramatic } \\
\hline & Soun & $\begin{array}{l}\text { No } \\
\text { Sound }\end{array}$ & Sounc & $\begin{array}{l}\text { No } \\
\text { Sound }\end{array}$ \\
\hline Distrust-Trust & 4.1 & 4.7 & 4.4 & 3.1 \\
\hline Tense-Relaxed & 5.5 & 5.6 & 5.6 & 4.4 \\
\hline Insincere-Sincere & 4.5 & 5.5 & 5.0 & 4.9 \\
\hline Disagree-Agree & 4.8 & 5.1 & 4.8 & 3.9 \\
\hline Unpersuasive-Persuasive & 3.8 & 4.4 & 4.4 & 3.4 \\
\hline Nervous-Calm & 6.1 & 5.9 & 5.9 & 4.8 \\
\hline Unclear-Clear & 4.2 & 3.6 & 3.6 & 4.6 \\
\hline Unintelligent-Intelligent & 4.6 & 5.2 & 5.3 & 5.0 \\
\hline
\end{tabular}

Note-The higher the mean the more positive the rating. Trait pairs are ordered negative-positive for the reader's convenience.

results indicate that the speaker was evaluated more favorably when he spoke seriously without sound effects than with sound effects, but just the reverse was true for dramatic speaking. In the latter case, the speaker was evaluated more favorably with sound effects.

The sixth mood rating (nervous/calm) was a marginal case in that it slightly deviated in its interaction pattern. The means were 6.1 for the serious/sound condition, 5.9 for the serious/no-sound condition, 5.9 for the dramatic/sound condition, and 4.8 for the dramatic/no-sound condition. This effect was significant $(\mathrm{F}=4.06, \mathrm{p}<.04)$.

There were two mood variables (unclear/clear) and unintelligent/intelligent) that were inconsistent with the preceding findings. The possibility exists that this deviation was due to the basic underlying dimensions of the mood ratings. The former mood ratings were concerned with a general emotional tone; the latter two pertained to the speaker's competence.

Only two significant main effects were obtained for the sound/no-sound manipulation. When the communication incorporated sound effects, the Ss rated the speaker as more calm and relaxed.

There were four significant main effects for the serious/dramatic manipulation. When the speaker spoke dramatically, the Ss rated him as more energetic, nervous, tense, and disagreeable.

There were a few main effects of Ss' sex. Females rated the speaker significantly more reliable, energetic, honest, illogical, and dislikable than did males.

\section{Attitude Measure}

The only significant effect for the attitude measure was a main effect of serious/dramatic $(F=4.38$, $\mathrm{p}<.04)$. The mean was higher when the speaker was serious in his voice quality (29.6) than when the speaker spoke dramatically (27.7).

\section{Recall Measure}

The only significant effect for recall was an interaction between sex of Ss and the serious-dramatic manipulation $(\mathrm{F}=6.39, \mathrm{p}<.01)$. Females exposed to the dramatic speech scored highest on recall (6.95). Females who were exposed to the serious speech scored lowest (6.15), with the males in between these two extremes. Males recalled best when exposed to the serious speech (6.58) and worst when exposed to the dramatic speech (6.30). The main effect of sound/no sound approached significance $(F=3.10, p<.07)$, with no-sound Ss scoring better (6.68) than sound Ss (6.31).

\section{DISCUSSION}

The results indicate that the manipulations had fairly strong and consistent effects on Ss' mood ratings. There seemed to be a strong element of "appropriateness" in the ratings. A serious voice style elicited relatively positive affect, adding sound effects detracted from this positive tone. However, when the voice style was dramatic, sound effects enhanced positive tone to about the level of the serious/no-sound condition. Clearly, the dramatic voice with no sound was less appealing than the serious voice with no sound.

In general, the results did not generalize to the findings of Galizio and Hendrick (1972) in regard to persuasion. In that study, musical accompaniment enhanced attitudinal acceptance. In the present study, sound effects neither enhanced nor reduced attitudinal acceptance. In fact, the main effect of serious/dramatic voice for attitudinal acceptance, when compared with the results for mood ratings, suggest a relative independence of affective and persuasive processes.

The present results are quite congenial to Leventhal's (1970) parallel response model. Leventhal argued that an emotion-provoking communication situation might cue off a variety of responses, including emotional reactions, differential learning, and attitude change. Each of these response systems may operate independently of the other systems. The systems work in parallel; sometimes they are positively correlated, sometimes negatively correlated, and sometimes apparently unrelated.

The present data strongly suggest relative independence of the affective and attitudinal systems for the particular experimental situations which were chosen. Thus, Leventhal's (1970) model may deserve serious consideration, particularly for attitude-change experiments in which some degree of emotionality is provoked. The difficult issue is a determination of the situations in which affect, attitude, and learning should be reasonably expected to be positively correlated vs those situations in which statistical independence should be expected. At present, there is no solution for this problem.

\section{REFERENCES}

Dabbs, J. M., \& Janis, I. L. Why does eating while reading facilitate opinion change? An experimental inquiry. Journal of Experimental Social Psychology, 1965, 1, 133-144.

Galizio, M., \& Hendrick, C. Effect of musical accompaniment on attitude: The guitar as a prop for persuasion. Journal of Applied Social Psychology, 1972, 2, 350-359.

Janis, I. L., Kaye, D., \& Kirschner, P. Facilitating effects of "eating-while-reading" on responsiveness to persuasive communications. Journal of Personality \& Social Psychology, 1965, 1, 181-186.

Leventhal, $H$. Findings and theory in the study of fear communications. In L. Berkowitz (Ed.), Advances in experimental social psychology. Vol. 5. New York: Academic Press, 1970.

(Received for publication March 21, 1974.) 